\title{
APLIKASI METODE ECONOMIC ORDER QUANTITY (EOQ) PADA PERSEDIAAN BAHAN PENOLONG REAGEN DENGAN PEMAKAIAN DAN WAKTU TUNGGU TAK TENTU
}

\author{
Ahmad Fatih Fudhla1, Susilowati Indah $\mathrm{SN}^{2}$ \\ 1,2Teknik Industri, Fakultas Teknik \\ Universitas Maarif Hasyim Latif, Sidoarjo, Indonesia \\ Email: fatih_fudhla@dosen.umaha.ac.id,indah.soeshy@gmail.com
}

\begin{abstract}
ABSTRAK
Bahan penolong reagen pada industri sabun dan produk-produk pembersih digunakan untuk menguji kualitas produk. Jika persediaan habis, maka kualitas hasil produksi tidak terkontrol. Sistem persediaan bahan reagen yang saat ini berjalan di PT. ABC, belum tertata dengan bagus. Pengecekan form pemakaian dilakukan dengan tidak terjadwal sehingga persediaan bahan reagen tersebut sering mengalami stockout yang mengakibatkan kerugian cukup besar. Pada penelitian ini, metode EOQ diaplikasikan untuk memperbaiki permasalahan tersebut. Pemakaian bahan reagen dan Lead Time bersifat fluktuatif dan tidak menentu. Setelah dilakukan simulasi dengan data pemakaian selama 2018, metode EOQ bisa mengurangi terjadinya stockout, sehingga total potensi penghematan mencapai $84 \%$ dibandingkan sistem yang berjalan saat ini.
\end{abstract}

Kata Kunci: EOQ, safety stock, stockout, reagen

\section{PENDAHULUAN}

PT ABC merupakan perusahaan yang bergerak dibidang produksi deterjen, pelembut pewangi pakaian, pembersih lantai, sabun batangan, sabun cair, dan lain sebagainya. Continuous production systems digunakan dalam seluruh proses fabrikasi. Oleh karena itu, ketersediaan bahan baku dan bahan pendukung menjadi sangat penting. Salah satu bahan pendukung utama dalam proses produksi yang digunakan untuk semua produk adalah bahan reagen. Bahan ini digunakan untuk menguji kualitas produk. Jika bahan ini persediaannya habis, maka kualitas hasil produksi tidak terkontrol. Hal ini mengakibatkan sejumlah produk yang dihasilkan berisiko tidak memenuhi standar kualitas. Jika hal tersebut sampai terjadi, maka produk tersebut harus dimusnahkan dan menjadi kerugian besar bagi perusahaan.

Berdasarkan data dari PT ABC, bahan reagen ini dalam setahun terakhir seringkali mengalami out of stock. Hal ini disebabkan oleh sistem persediaan yang belum tertata dengan baik. pengadaan baru dilakukan saat barang sudah habis yang diperparah kondisi lead time penerimaan bisa beberapa hari dan tidak menentu. Oleh karena itu diperlukan perbaikan sistem persediaan yang bisa mengakomodir kondisi tersebut.

Di dalam penelitian ini, metode manajemen persediaan Economic Order Quantity (EOQ) untuk uncertain demand dan uncertain lead time digunakan untuk memperbaiki sistem persediaan bahan reagen. EOQ adalah metode penentuan jumlah pesanan yang dapat meminimumkan total biaya persediaan serta untuk mencari berapa total bahan yang tetap untuk dibeli dalam setiap kali pembelian untuk menutup kebutuhan selama satu periode (Guga \& Muja, 2015).

\section{METODE PENELITIAN}

\section{Persediaan}

Persediaan adalah sumber daya menganggur yang menunggu proses lebih lanjut (berupa kegiatan produksi, kegiatan pemasaran, atau kegiatan konsumsi) (Yeh, 2012). Keberadaan inventori tidak bisa dihindarkan karena mekanisme pemenuhan permintaan yang tidak dapat dilakukan dengan segera pada saat permintaan terjadi, serta untuk mengadakan barang-barang tidak dapat dilakukan secara spontan tetapi diperlukan tenggang waktu untuk memperolehnya (Singh dan Verma, 2018).

Jenis-Jenis barang yang seringkali jadi persediaan (Yen, 2012 dan Muchaendepi et. al, 2019).

1. Persediaan bahan baku

Bahan baku merupakan masukan awal proses transformasi produksi, keberadaan bahan baku sangat menentukan kelancaran proses produksi. 
2. Persediaan barang setengah jadi

Bentuk peralihan bahan baku menjadi produk jadi. Terjadi karena karakteristik proses yang memang panjang atau akibat lintasan produksi yang tidak seimbang

3. Persediaan barang jadi

Hasil akhir proses transformasi produksi

4. Persediaan bahan penolong (supplies) Untuk membantu kegiatan proses produksi

5. Persediaan suku cadang (spare part)

Menunjang dan menjamin keandalan mesin dan peralatan yang menopang aktivitas operasi perusahaan. Seperti suku cadang mesin produksi, transporter dalam lingkungan produksi, maupun transporter pengangkut atau distribusi barang jadi.

\section{Formulasi Economic Order Quantity (EOQ) untuk permintaan dan waktu tunggu lead time tidak menentu.}

Economic Order Quantity (EOQ) merupakan metode pengaturan persediaan yang dilakukan dengan mengevaluasi secara realtime kondisi level persediaan, jika menyentuh titik "pemesanan kembali" / Re Order Point (ROP) maka harus dilakukan pengadaan sebesar ukuran lot tertentu $(\mathrm{Q})$.

Di dalam Chao (1992), Total Biaya Penyimpanan, didapatkan dengan rumus:

$T I C=T H C+T O C$

$T I C=A \cdot H+f \cdot S$

Dimana :

TIC : Total Biaya Persediaan / Total of Inventory Cost (Rp)

THC : Total of Holding Cost / total biaya simpan (Rp) yang didapat dari rata-rata volume penyimpanan dikalikan dengan biaya simpan perunit pertahun

TOC : Total of Ordering Cost / total biaya pemesanan (Rp) yang didapatkan dari frekuensi pemesanan dikalikan dengan biaya tiap pemesanan.

A : Rata-rata volume persediaan dalam setahun (Unit/tahun)

$\mathrm{H}$ : biaya penyimpanan (Rp/Unit/tahun)

$\mathrm{f}$ : Frekuensi Pembelian yang dilakukan oleh perusahaan

$\mathrm{S} \quad$ : biaya pemesanan (Rp/ Pemesanan)

Pada EOQ, ukuran lot optimal didapatkan dari trade off antara total biaya penyimpanan dan total biaya simpan (holding). Di dalam Chao, (1992); Oussama et. al., (2013); Chopra dan Meidl, (2002); serta Nuriszal, F. dan Anshori, M. (2019), ukuran lot optimal dan Re Order Point didapatkan dengan rumus;

$\mathrm{Q}^{*}=\sqrt{\frac{2 \cdot D \cdot S}{H}}$

Dimana;

$\begin{array}{ll}\mathrm{Q}^{*} & \begin{array}{l}\text { : Ukuran Lot Optimal (unit) } \\ \mathrm{D}\end{array} \\ \mathrm{i} \text { Demand/permintaan selam satu } \\ \mathrm{tahun}(\mathrm{unit}) \\ \mathrm{S} & \begin{array}{l}\text { : Biaya pemesanan/Ordering Cost } \\ \text { (Rp/order) }\end{array} \\ \mathrm{H} & \begin{array}{l}\text { :Biaya Simpan/holding cost } \\ \text { (Rp/unit/tahun) }\end{array}\end{array}$

Dan Re Order Point (ROP);

Re Order Point pada hakikatnya adalah sejumlah unit persediaan yang harus ditahan sehingga selama masa lead time (waktu tunggu antara order hingga barang diterima) tidak terjadi stockout. Sehingga, ROP didapatkan dengan rumus; $\mathrm{ROP}=d \cdot L T$
Dimana;
d : permintaan setiap periode (assume konstan)
LT : periode Lead Time

Jika permintaan dan lead time tidak tentu, maka ditambahkan safety stock

$$
\begin{array}{ll}
\mathrm{ROP} & =\bar{d} \cdot \overline{L T}+s S \\
& \text { Dimana; } \\
\bar{d} \quad \text { : rata-rata permintaan setiap } \\
& \quad \text { periode } \\
\overline{L T} \quad: \text { rata-rata periode lead time } \\
\text { ss } \quad \text { : safety stock, }
\end{array}
$$

Jika permintaan fluktuatif lead time tetap

$$
\text { Ss } \quad \begin{array}{ll}
=Z_{\alpha} \cdot \sigma_{d L T} \\
\text { dimana; } \\
Z_{\alpha} \quad \text { : nilai Z pada distribusi normal } \\
& \text { standard dengan probabilitas 1- } \alpha \\
& \begin{array}{l}
\text { : standar deviasi permintaan } \\
\text { selama Lead Time }
\end{array}
\end{array}
$$

dan jika permintaan dan lead time fluktuatif, safety stock menjadi

$$
\begin{aligned}
& =Z_{\alpha} \sqrt{\overline{L T} \times \sigma_{d}^{2}+\bar{d}^{2} \times \sigma_{L T}^{2}} \\
& \text { dimana; } \\
& \sigma_{d} \quad: \text { standar deviasi permintaan } \\
& \sigma_{L T} \quad: \text { standar deviasi Lead Time }
\end{aligned}
$$

\section{HASIL DAN PEMBAHASAN}

\section{Data Permintaan Bahan Reagen}

Jenis bahan reagen yang dijadikan obyek penelitian terdiri dari 6 jenis bahan. Sebagaimana ditunjukkan pada tabel 1 dibawah ini. Jumlah Pemakaian bahan reagen terbesar adalah $\mathrm{NaIO} 4$ disusul AgNO3 dan Morpholin, baik secara harian maupun total dalam satu tahun. Sedangkan waktu tunggu pemesanan (Lead Time) setiap bahan berlangsung fluktuatif, namun satu item dengan yang lain memiliki rata-rata hari tunggu yang tidak jauh berbeda. 
Tabel 1. Jenis dan satuan bahan Reagen

\begin{tabular}{|c|c|c|c|c|c|c|c|}
\hline $\mathrm{No}$ & $\begin{array}{l}\text { Bahen } \\
\text { Penuriary } \\
\text { Kealias }\end{array}$ & Unit/Sthan & $\begin{array}{c}\text { limith } \\
\text { Pendaian } \\
\text { selame } \\
\text { vusis } \\
\text { lunit| }\end{array}$ & 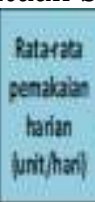 & $\begin{array}{l}\text { Standar } \\
\text { Deviagi } \\
\text { peralaban } \\
\text { harien }\end{array}$ & $\begin{array}{l}\text { Reta } \\
\text { rath } \\
\text { lew } \\
\text { Tine } \\
\text { lhart }\end{array}$ & 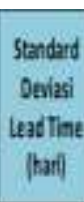 \\
\hline 1 & $\begin{array}{l}\text { Kertzas Saning } \\
\text { lapen }\end{array}$ & Lember & 2293 & 6.3 & 6.2 & 5 & 144 \\
\hline 2 & Apsot & Gram & 16432 & 4.6 & 26 & 4 & 11 \\
\hline 3 & PH Sick & Pad & 1353 & 3.7 & 30 & 5 & 12 \\
\hline 4 & Aglos & Gram & 6697 & 183 & 19.1 & 4 & 08 \\
\hline 5 & Morphoin & $\mathrm{NI}$ & 6645 & 182 & 18.8 & 5 & 12 \\
\hline 6 & $\mathrm{NalO4}$ & Grem & 7650 & 210 & 24.3 & 5 & 1 \\
\hline
\end{tabular}

Detail Data Historis pemakaian bahan tersebut disajikan pada Gambar 1. Pada Grafik tersebut dapat dilihat bahwa pemakaian bahan reagen di perusahaan $\mathrm{PT}$. ABC mengalami fluktuasi tiap bulannya.

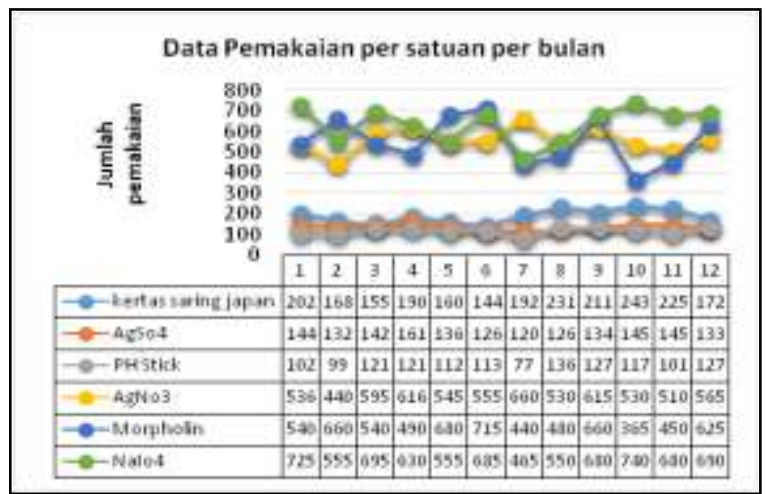

Gambar 1. Grafik Pemakaian Bahan Reagen Bulan Januari - Desember 2018.

Untuk pemakaian bahan reagen NaIo4 paling tinggi pada bulan Maret 2018 yaitu sebesar 695 Gram sedangkan pemakaian paling rendah pada bulan Agustus 2018 yaitu sebanyak 550 Gram. Sedangkan untuk PH Stick pemakaian paling tinggi pada bulan Agustus yaitu sebanyak 136 pack dan terendah pada bulan Juni yaitu sejumlah 77 Pack. Begitu juga bahan reagen yang lainya mengalami pemakaian yang tidak menentu dikarenakan faktor produksi yang berjalan terus menerus dan hasil uji kualitas produk yang tidak bisa dipastikan

\section{Identifikasi Komponen Biaya Identifikasi Biaya Pemesanan}

Biaya Pemesanan merupakan semua biaya yang timbul ketika dilakukannya pemesanan. Dalam penelitian ini, biaya pemesanan terdiri dari biaya pengiriman barang (biaya administrasi, biaya operasional PPJK ) dan biaya proses pemesanan (pembuatan faktur, faxmile, telepon dll) dengan rincian sebagai berikut :

Tabel 2. Data biaya pemesanan bahan reagen

\begin{tabular}{|c|c|c|}
\hline No & Jenis Biaya & $\begin{array}{c}\text { Biaya (Rp) } \\
\text { per pesan } \\
\text { per volume } \\
\text { order }\end{array}$ \\
\hline \multicolumn{3}{|c|}{ Biaya Pengiriman Barang } \\
\hline 1 & Administrasi & 500,00 \\
\hline 2 & Biaya Operational & $1.000,00$ \\
\hline 3 & Pemeriksaan & $1.000,00$ \\
\hline \multicolumn{3}{|c|}{ Biaya Proses Pemesanan } \\
\hline 4 & Biaya Surat menyurat (Faktur) & $1.500,00$ \\
\hline 5 & $\begin{array}{l}\text { Biaya Komunikasi (Telepon, } \\
\text { Faxmail, Internet dlI) }\end{array}$ & $10.000,00$ \\
\hline \multicolumn{2}{|r|}{ Total } & $14.000,00$ \\
\hline
\end{tabular}

Total biaya pemesanan tiap kali order bahan reagen adalah $\mathrm{Rp} 14.000,00$, biaya pemesanan yang paling besar adalah pada biaya komunikasi dikarenakan untuk setiap kali pemesanan bahan reagen jika bahan belum diterima selalu di follow up sampai bahan reagen yang dipesan datang.

\section{Identifikasi Biaya Penyimpanan}

Dalam penelitian ini, pihak perusahaan membebankan biaya penyimpanan per unit per tahun sebesar 5\% dari harga reagen per unit, yang terdiri terdiri dari biaya sewa gudang $1 \%$ dan biaya atau beban risiko kerusakan bahan reagen 4\%. Rincian harga dan biaya penyimpanan masingmasing ditunjukkan pada tabel berikut.

Tabel 3. Daftar harga rata-rata tahun 2018 bahan reagen dan biaya penyimpanan

\begin{tabular}{|c|l|c|c|c|}
\hline \multirow{2}{*}{ No } & \multirow{2}{*}{ Bahan Reagent } & \multirow{2}{*}{ Satuan } & Harga & Biaya Penyimpanan \\
\cline { 4 - 5 } & & & Rp/unit & Rp/unit/tahun \\
\hline 1 & Kertas Saring Japan & Lembar & 3.000 & 150 \\
\hline 2 & AgS04 & Gram & 37.800 & 1.890 \\
\hline 3 & PH Stick & Pack & 66.000 & 3.300 \\
\hline 4 & AgNo3 & Gram & 9.400 & 470 \\
\hline 5 & Morpholin & Ml & 670 & 34 \\
\hline 6 & Nalo4 & Gram & 2.789 & 139 \\
\hline
\end{tabular}

\section{Perhitungan Biaya Persediaan Sistem Berjalan}

Ketika persediaan bahan reagen mengalami stock out, akan berimplikasi pada tertahannya uji kualitas produk. Hal ini akan memunculkan risiko produk yang sedang berjalan kualitasnya tidak sesuai standar. Oleh karena itu, ketika stock out terjadi, pihak perusahaan membebankan risiko tersebut dengan memunculkan biaya stockout sebesar $2 \%$ harga total lot pengadaan bahan reagen yang ditunggu dikalikan periode hari stockout terjadi.

Sehingga perhitungan total biaya persediaan dihitung dengan rumus :

$T I C=A \cdot H+f \cdot S+B S$

Dimana:

BS : Biaya stockout (Rp) yang dihitung dari ( $2 \%$ dari jumlah periode stockout $\times$ ukuran lot) 
Rata-rata persediaan dan frekuensi pengadaan untuk setiap item disajikan pada tabel 4 .

Tabel 4. Rata-rata persediaan pada sistem yang berjalan saat ini dan frekuensi pembelian tahun

\begin{tabular}{|l|c|c|c|c|}
\hline \multirow{2}{*}{ Bahan reagent (unit) } & $\begin{array}{c}\text { Rata-rata } \\
\text { Persediaan } \\
\text { (unit/tahun) }\end{array}$ & $\begin{array}{c}\text { Frekuensi } \\
\text { Pembelian }\end{array}$ & $\begin{array}{c}\text { Ukura } \\
\mathrm{n} \text { Lot } \\
\text { (unit) }\end{array}$ & $\begin{array}{c}\text { Jumlah } \\
\text { periode } \\
\text { stockout } \\
\text { (hari) }\end{array}$ \\
\hline $\begin{array}{l}\text { Kertas Saring japan } \\
\text { (Lembar) }\end{array}$ & 137,87 & 8 & 280 & 8 \\
\hline AgS04 (Gram) & 56,68 & 15 & 100 & 18 \\
\hline PH Stick (Pack) & 51,98 & 13 & 100 & 20 \\
\hline AgNo3 (Gram) & 359,03 & 11 & 500 & 17 \\
\hline Morpholin (ml) & 493,22 & 6 & 1000 & 15 \\
\hline Nal04 (Gram) & 509,27 & 7 & 1000 & 8 \\
\hline
\end{tabular}

PH stick menjadi bahan reagen yang mengalami periode stockout terlama yakni 20 hari. Kertas saring dan NaIO4 menjadi yang paling rendah. Sebagaimana disajikan didalam tabel 4 tersebut, kesemua bahan reagen selama tahun 2018 mengalami stockout. Hal ini menunjukkan bahwa sistem manajemen persediaan yang saat ini berjalan, memiliki banyak potensi untuk dilakukannya perbaikan.

Bedasarkan persamaan di atas, dengan data yang tersaji pada tabel 4. Total Biaya Persediaan (TIC) bisa diperhitungkan sebagaimana ditunjukkan pada Tabel 5

Tabel 5. Total Biaya Persediaan dengan sistem

\begin{tabular}{|c|l|c|c|c|c|}
\hline \multirow{2}{*}{ No } & \multirow{2}{*}{ Bahan Reagent } & $\begin{array}{c}\text { Komponen } \\
\text { Biaya } \\
\text { Holding }\end{array}$ & $\begin{array}{c}\text { Komponen } \\
\text { biaya } \\
\text { pemesanan }\end{array}$ & $\begin{array}{c}\text { Komponen } \\
\text { Biaya } \\
\text { Stockout }\end{array}$ & \multirow{2}{*}{ Total (Rp) } \\
\cline { 3 - 5 } & $\mathrm{Rp}$ & $\mathrm{Rp}$ & $\mathrm{Rp}$ & \\
\hline 1 & Kertas Saring Japan & 20,681 & 112,000 & 134,400 & 267,081 \\
\hline 2 & AgS04 & 107,125 & 210,000 & $1,360,800$ & $1,677,925$ \\
\hline 3 & PH Stick & 171,534 & 182,000 & $2,640,000$ & $2,993,534$ \\
\hline 4 & AgNo3 & 168,744 & 154,000 & $1,598,000$ & $1,920,744$ \\
\hline 5 & Morpholin & 16,769 & 84,000 & 201,000 & 301,769 \\
\hline 6 & Nal04 & 70,789 & 98,000 & 446,240 & 615,029 \\
\hline \multicolumn{5}{|c|}{$\mathrm{TIC}$} & $7,776,082$ \\
\hline
\end{tabular}

Pada Tabel 5 dapat dilihat bahwa jumlah total biaya persediaan dengan sistem manajemen persediaan yang digunakan perusahaan saat ini adalah sebesar Rp 7.776.082,-. Biaya persediaan yang paling tinggi adalah pada bahan reagen $\mathrm{PH}$ Stick yaitu sebesar Rp 2.993.534,-sedangkan biaya persediaan paling rendah pada bahan reagen kertas saring japan yaitu sebanyak Rp 267.081,-Bahan reagen tersebut sudah termasuk dengan penambahan biaya stock out bahan yang muncul karena keterlambatan datangnya pesanan.

\section{Aplikasi metode Economic Order Quantity (EOQ)}

Berdasarkan data pada tabel 1, tabel 2 dan tabel 3 dapat dihitung kuantitas pembelian optimal dengan menggunakan rumus :

$\mathrm{Q}^{*}=\sqrt{\frac{2 \cdot D \cdot S}{H}}$

Sehingga kuantitas Pembelian Optimal Kertas saring japan $\mathrm{sbb}$ :

$$
\begin{aligned}
& Q^{*}=\sqrt{\frac{2 \times 2293 \times 14000}{150}} \\
&=\sqrt{\frac{64204000}{150}} \\
&=\sqrt{428026,667} \\
&=654,2375 \\
& \text { dibulatkan menjadi 654 Lembar }
\end{aligned}
$$

Untuk bahan reagen yang lain, rekapitulasi Lotsize Optimal, disajikan pada Tabel 6 .

Tabel 6. Data Kuantitas Optimal Pemesanan berikut :

\begin{tabular}{|l|c|}
\hline \multicolumn{1}{|c|}{ Bahan reagen (unit) } & $\begin{array}{c}\text { Ukuran Lot } \\
\text { E0Q } \\
\text { (Unit) }\end{array}$ \\
\hline Kertas Saring japan (Lembar) & 654 \\
\hline AgSo4 ( Gram ) & 156 \\
\hline PH Stick ( Pack ) & 107 \\
\hline AgNo3 ( Gram ) & 632 \\
\hline Morpholin ( Ml ) & 2339 \\
\hline NaIo4 (Gram ) & 1241 \\
\hline
\end{tabular}

Titik Pemesanan Kembali/ROP (Re order Point) lead time dan pemakaian tak menentu dihitung dengan persamaan;

$\mathrm{ROP}=\overline{\mathrm{d}} \times \overline{\mathrm{LT}}+\mathrm{SS}$

$\mathrm{ROP}=\overline{\mathrm{d}} \times \overline{L T}+\mathrm{Z} \alpha \sqrt{\overline{L T} \times \sigma_{d}^{2}+\bar{d}^{2} \times \sigma_{L T}^{2}}$

Dengan $\alpha=0.05$, ROP (Re Order Point) atau titik pemesanan kembali untuk bahan reagen kertas saring japan adalah sebagai berikut :

ROP

$=$

$6,334254144 \times 5+1.64 X \sqrt{5 \times 6,2^{2}+6,3^{2} \times 1,4^{2}}$ ROP $=58,5$

Dibulatkan menjadi 59 Lembar

ROP bahan reagen lainnya, ditunjukkan pada Tabel 7. 
Tabel 7. Rekapitulasi Data ROP Bahan Reagen

\begin{tabular}{|l|c|}
\hline \multicolumn{1}{|c|}{ Bahan reagen (unit) } & $\begin{array}{c}\text { ROP ( dalam } \\
\text { unit) }\end{array}$ \\
\hline Kertas Saring japan ( Lembar) & 59 \\
\hline AgSo4 ( Gram ) & 30 \\
\hline PH Stick ( Pack ) & 32 \\
\hline AgNo3 ( Gram ) & 141 \\
\hline Morpholin ( Ml ) & 169 \\
\hline NaIo4 (Gram ) & 200 \\
\hline
\end{tabular}

\section{Perhitungan Biaya Persediaan}

Dengan dasar data pemakaian harian selama 2018, ukuran Lot sebagaimana Tabel 6 dan ROP dari Tabel 7, didapatkan rata-rata persediaan dan frekuensi pemesanan untuk setiap item reagen sebagaimana disajikan pada Tabel 8 .

Tabel 8. Hasil simulasi dengan EOQ

\begin{tabular}{|l|c|c|c|}
\hline Bahan reagen & $\begin{array}{c}\text { Rata- } \\
\text { rata } \\
\text { Persedi } \\
\text { aan }\end{array}$ & $\begin{array}{c}\text { Frekuensi } \\
\text { Pembelian }\end{array}$ & $\begin{array}{c}\text { Peri } \\
\text { ode } \\
\text { Stoc } \\
\text { kout }\end{array}$ \\
\hline $\begin{array}{l}\text { Kertas Saring } \\
\text { japan ( Lembar ) }\end{array}$ & 327 & 4 & 0 \\
\hline AgSo4 (Gram ) & 78 & 10 & 0 \\
\hline PH Stick ( Pack ) & 54 & 12 & 0 \\
\hline AgNo3 (Gram ) & 316 & 9 & 0 \\
\hline Morpholin ( Ml ) & 1,170 & 3 & 0 \\
\hline NaIo4 (Gram ) & 621 & 6 & 0 \\
\hline
\end{tabular}

Dengan pendekatan EOQ, menggunakan data pemakaian reagens tahun 2018, simulasi

Tabel 9. Rekapitulasi Biaya Persediaan dengan EOQ menunjukkan tidak terjadi stockout. Berdasarkan hasil simulasi pada Tabel 8, dengan menggunakan formula TIC, didapatkan perhitungan Total Biaya persediaan sebagaimana ditunjukkan pada Tabel 9.

$$
\begin{aligned}
\mathrm{TIC}= & A \cdot H+f \cdot S+B S \\
\mathrm{TIC}_{\text {kertas saring japan }} & (327 \text { unit } \cdot \text { Rp } 150,-)+ \\
& (4 \cdot \text { Rp } 14.000,-)+(2 \% . \\
& 0 \text { hari } \cdot 645 \text { unit })
\end{aligned}
$$

\begin{tabular}{|c|c|c|c|c|c|c|c|c|c|c|c|c|}
\hline \multirow{3}{*}{ No } & \multirow{3}{*}{$\begin{array}{l}\text { Bahan } \\
\text { Reagen }\end{array}$} & \multirow{3}{*}{$\begin{array}{l}\text { unit/ } \\
\text { satuan }\end{array}$} & \multicolumn{3}{|c|}{ Komponen Biaya Holding } & \multicolumn{3}{|c|}{ Komponen biaya pemesanan } & \multicolumn{3}{|c|}{ Komponen Biaya Stockout } & \multirow{3}{*}{ total $(\mathrm{Rp})$} \\
\hline & & & $\begin{array}{l}\text { Rata- } \\
\text { rata } \\
\text { penyimp } \\
\text { anan }\end{array}$ & $\begin{array}{l}\text { Biaya } \\
\text { penyimp } \\
\text { anan }\end{array}$ & $\begin{array}{l}\text { Biaya } \\
\text { Holding } \\
\text { total }\end{array}$ & \multirow[t]{2}{*}{$\begin{array}{l}\text { Frek. } \\
\text { order }\end{array}$} & $\begin{array}{l}\text { Biaya } \\
\text { per } \\
\text { pemes } \\
\text { anan } \\
\end{array}$ & $\begin{array}{l}\text { Biaya } \\
\text { pemesan } \\
\text { an }\end{array}$ & $\begin{array}{l}\text { Ukuran } \\
\text { Lot }\end{array}$ & $\begin{array}{l}\text { Jumlah } \\
\text { periode } \\
\text { stockout }\end{array}$ & $\begin{array}{l}\text { Biaya } \\
\text { stockout }\end{array}$ & \\
\hline & & & $\begin{array}{l}\text { (unit/tah } \\
\text { un) }\end{array}$ & $\begin{array}{l}\text { Rp/unit/ } \\
\text { tahun }\end{array}$ & (Rp) & & $\begin{array}{l}\text { Rp/pe } \\
\text { san }\end{array}$ & $\mathrm{Rp}$ & Unit & hari & $\mathrm{Rp}$ & \\
\hline 1 & $\begin{array}{l}\text { Kertas } \\
\text { Saring } \\
\text { Japan }\end{array}$ & Lembar & 327 & 150 & 49,050 & 4 & 14,000 & 56,000 & 654 & - & - & 105,050 \\
\hline 2 & AgSo4 & Gram & 78 & 1,890 & 147,420 & 10 & 14,000 & 140,000 & 156 & - & - & 287,420 \\
\hline 3 & PH Stick & Pack & 54 & 3,300 & 176,550 & 12 & 14,000 & 168,000 & 107 & - & - & 344,550 \\
\hline 4 & AgNo3 & Gram & 316 & 470 & 148,520 & 9 & 14,000 & 126,000 & 632 & - & - & 274,520 \\
\hline 5 & $\begin{array}{l}\text { Morpholi } \\
n\end{array}$ & $\mathrm{Ml}$ & 1,170 & 34 & 39,763 & 3 & 14,000 & 42,000 & 2339 & - & - & 81,763 \\
\hline 6 & NaIo4 & Gram & 621 & 139 & 86,250 & 6 & 14,000 & 84,000 & 1241 & - & - & 170,250 \\
\hline \multicolumn{12}{|c|}{ TIC } & $1,263,553$ \\
\hline
\end{tabular}

$\mathrm{TIC}_{\text {kertas saring japan }}=$

$$
\begin{aligned}
& (R p 49.050,-)+ \\
& \quad(R p 56.000,-)+(R p 0,-)
\end{aligned}
$$

$\mathrm{TIC}_{\text {kertas saring japan }}=R p$ 105.050,- 


\section{Analisis Perbandingan}

Perbandingan total biaya persediaan bahan reagen antara manajemen persediaan yang dijalankan perusahaan saat ini dengan metode EOQ, serta potensi penghematan yang didapatkan dari data pemakaian bahan selama 2018 disajikan pada tabel 10.

Tabel 10. Rekapitulasi perbandingan Total biaya Persediaan kondisi existing dan EOQ

\begin{tabular}{|c|c|c|c|c|c|}
\hline \multirow{2}{*}{ Bahan reagent } & \multirow{2}{*}{$\begin{array}{c}7 C_{\text {essers }} \\
\text { (Pq) }\end{array}$} & \multirow{2}{*}{$\begin{array}{c}\mathrm{TC}_{\mathrm{EDQ}} \\
\text { (Rp) }\end{array}$} & \multicolumn{2}{|c|}{ Selisin } & \multirow{2}{*}{ Keterangan } \\
\hline & & & $\mathrm{Rp}$ & $\%$ & \\
\hline Kertas Saring lapan & 267,081 & 105,050 & 162,081 & $61 \%$ & TIG \\
\hline $\mathrm{AgSO} 4$ & $1,677,925$ & 287,420 & $1,390,505$ & $83 \%$ & $\mathrm{TIC}_{\mathrm{En}}$ Lebih renda \\
\hline PHStick & $2,993,534$ & 344,550 & $2,648,984$ & $88 \%$ & $\mathrm{TIC} \mathrm{CDQ}_{\mathrm{DQ}}$ Lebih rend \\
\hline $\mathrm{AgNo3}$ & $1,920,744$ & 274,520 & $1,646,224$ & $86 \%$ & $\mathrm{TIC}_{\mathrm{SDQ}}$ Lebih rend \\
\hline Morphoin & 301,769 & 81,763 & 220,006 & $73 \%$ & $\mathrm{TIC} \mathrm{C}_{\mathrm{SD}}$ Lebih rendah \\
\hline Nalo4 & 615,029 & 170,250 & 444,779 & $72 \%$ & $\mathrm{TIC}_{\mathrm{ED}}$ Lebih rendah \\
\hline Total & $7,776,082$ & $1,268,558$ & $6,512,529$ & 8486 & TICoglebihrend \\
\hline
\end{tabular}

Dari tabel 10 dapat diketahui bahwa total biaya persediaan bahan reagen jika menggunakan pendekatan EOQ bisa menekan biaya hingga 84\%. Semua item reagen menunjukkan total biaya bisa ditekan. Penghematan biaya persediaan terbesar didapatkan dari item PH stick yang mencapai $88 \%$, sedangkan yang terendah sebesar $61 \%$ pada Kertas Saring Japan. Potensi penghematan bisa diraih dengan pendekatan EOQ karena, metode ini bisa mengeliminir terjadinya stockout.

\section{PENUTUP}

Sistem persediaan bahan reagen yang saat ini diterapkan di PT. ABC adalah pengecekan form pemakaian bahan reagen, yang dilakukan dengan tidak terjadwal. Sehingga persediaan bahan reagen tersebut sering mengalami stockout dan diperparah oleh penentuan timing untuk order bahan reagen juga mengalami keterlambatan. Dengan metode EOQ bisa mengeliminir terjadinya stockout, sehingga total potensi penghematan mencapai $84 \%$.

Dalam penelitian ini, perhitungan biaya akibat stock out diasumsikan $2 \%$ perhari dari nilai ukuran lot. Dimana, biaya stock out aktual seharusnya lebih besar. Perlu dilakukan kajian lebih mendalam pada penelitian selanjutnya mengenai semua detail biaya yang timbul akibat ketiadaan bahan reagent.

\section{DAFTAR PUSTAKA}

Ammar, O. Ben, Dolgui, A., Hnaien, F., \& Louly, M. A. (2013). Supply planning and inventory control under lead time uncertainty: A review. IFAC Proceedings Volumes, 46(9), 359-370.

Chao, H. (1992). The EQQ model with stochastic demand and discounting. European Journal of Operational Research, 59(3), 434-443.

Chauhan, N. S., \& Ahmad, S. (2012). Optimizing Cycle Time of Dvd-R Injection Moulding Machine. International Journal of Engineering Science and Technology, 4(5), 1982-1990.

Chopra, S., \& Meindl, P. (2001). Demand Forecasting in a Supply Chain, chapter 7. Supply Chain Management: Strategy, Planning, and Operations. Pearson, Prentice Hall, Upper Saddle River, New Jersey, 171204.

Guga, E., \& Muja, O. (2015). Inventory Management Through EOQ Model (A case study of shpreza, LTD, Albania). International Journal of Economic, Commerce and Management, 3(12), 174182.

Macias Vargas, C. (2019). Defining a Machine Learning implementation for demand forecasting in Dental Tracking System.

Muchaendepi, W., Mbohwa, C., Hamandishe, T., \& Kanyepe, J. (2019). Inventory Management and Performance of SMEs in the Manufacturing Sector of Harare. Procedia Manufacturing, 33, 454-461.

Nuriszal, F., \& Anshori, M. (2019). Perencanaan Persediaan Bahan Baku Untuk Produk Semen Instan di PT. VWX. JISO: Journal of Industrial and Systems Optimization, 2(1), 18-22. 